\title{
Metabolism of Schizosaccharomyces pombe under reduced osmotic stress conditions afforded by fed-batch alcoholic fermentation of white grape must
}

\author{
Roca-Domènech G. ${ }^{\mathrm{a}}$, Cordero-Otero R. ${ }^{\mathrm{a}}$, Rozès N. ${ }^{\mathrm{a}}$, Cléroux M. ${ }^{\mathrm{b}}$, Pernet A. ${ }^{\mathrm{b}}$, Mira de Orduña R. ${ }^{\mathrm{b}, *}$ \\ a Department of Biochemistry and Biotechnology, University Rovira i Virgili, Tarragona, Spain \\ ${ }^{\mathrm{b}}$ University of Western Switzerland, Changins College for Viticulture and Enology, Nyon, Switzerland
}

\section{A R T I C L E I N F O}

\section{Keywords:}

Schizosaccharomyces pombe

Grape wine

Non-Saccharomyces

Fed-batch

Acetic acid

\begin{abstract}
A B S T R A C T
Strains of Schizosaccharomyces pombe are being increasingly investigated with regards to their grape winemaking potential either in combination with the typical production yeast, Saccharomyces cerevisiae, or in monoseptic fermentations. Their ethanol tolerance and ability to degrade L-malic acid is oenologically convenient but contrasts with the comparatively high acetic acid and acetaldehyde formation potential which is considered undesirable, especially in white winemaking. The purpose of this work was to investigate the performance of a selected $S$. pombe strain in monoseptic femerntations of white grape must. Traditional batch fermentations were compared with an innovative and automated fed-batch fermentation technique were sugar concentrations are kept low during fermentations to decrease sugar induced osmotic stress. Because of its known effect on growth and ethanol tolerance, the effect of $\mathrm{Mg}$ was also tested. While $\mathrm{Mg}$ supplementation was not shown to significantly influence residual values of sugars, ethanol, glycerol, organic acids and acetaldehyde, the application of the fed-batch technique led to a fundamental change in yeast physiology. While glycerol values were only slightly reduced, the fed-batch approach allowed obtaining wines devoid of acetic acid whose levels were considerable in wines produced by the traditional batch technique $(0.6 \mathrm{~g} / \mathrm{L})$. The work demonstrates that the acetic acid metabolism of $S$. pombe is associated to sugar induced osmotic stress such as for $S$. cerevisiae, too, and may be controlled by application of suitable fermentation techniques for winemaking.
\end{abstract}

\section{Introduction}

Alcoholic fermentation (AF) is a complex biochemical process based on the microbial conversion of sugars to ethanol, carbon dioxide and fermentation by-products, such as glycerol, organic acids and carbonyls (Pretorius, Van der Westhuizen, \& Augustyn, 1999). In winemaking, Saccharomyces cerevisiae is typically considered the main responsible for $\mathrm{AF}$, whereas non-Saccharomyces yeasts have usually been considered as 'spoilage' yeasts because of their association with products presenting organoleptic defects (Ciani, Comitini, Mannazzu, \& Domizio, 2010; Contreras et al., 2014; Fleet, Lafon-Lafourcade, \& Ribereau-Gayon, 1984). The excessive production of acetic acid, acetaldehyde, and ethyl acetate is among the potential undesirable metabolic activities of nonSaccharomyces wine yeasts (Ciani et al., 2010).

However, growing anecdotal and experimental evidence obtained over the last decade suggests that the winemaking potential of nonSaccharomyces yeast has been undervalued and that selected strains may play a relevant role with regards to aroma complexity and final wine quality (Ciani et al., 2010; Ciani \& Maccarelli, 1998; Padilla, Gil, \&
Manzanares, 2016). Schizosaccharomyces pombe is of particular interest. Unlike most other non-Saccharomyces, $S$. pombe can ferment grape musts to dryness because of its high alcohol and $\mathrm{SO}_{2}$ tolerance (Koukou, Tsoukatos, \& Drainas, 1990; Queiroz \& Pareilleux, 1990). In addition to its fermentation performance, it has several interesting metabolic capabilities, too. Notably, S. pombe strains have been shown to convert Lmalic acid into ethanol and $\mathrm{CO}_{2}$, to reduce gluconic acid (Peinado, Maestre, Mauricio, \& Moreno, 2009), to express urease (Benito et al., 2013; Benito et al., 2016; Silva et al., 2003; Taillandier, Gilis, \& Strehaiano, 1995) and to produce significant amounts of cell wall polysaccharides (Domizio, Liu, Bisson, \& Barile, 2017). Over the last years, several studies considering the nutrition, growth and metabolism of S. pombe (Hoffman, Wood, \& Fantes, 2015; Petersen \& Russell, 2016) have been presented. However, fundamental aspects of the metabolism of $S$. pombe such as its response to osmotic stress remain unknown. Recently, it was shown that reducing sugar induced osmotic stress during alcoholic fermentation by application of a fed-batch approach led to fundamental changes in the metabolism of $S$. cerevisiae that may be favourable for wine quality (Frohman \& Mira de Orduña, 2013).

\footnotetext{
* Corresponding author at: University of Western Switzerland, Changins College for Viticulture and Enology, Rte de Duillier 50, CH-1260-1 Nyon, Switzerland.

E-mail address: ramon.mira@changins.ch (R. Mira de Orduña).
} 
Notably, the formation of acetic acid was greatly reduced.

The aim of the current work was to investigate the metabolic response of $S$. pombe under reduced osmotic stress conditions attained by an automated fed-batch technique (Frohman \& Mira de Orduña, 2018) allowing alcoholic fermentation at constant and reduced sugar levels. The kinetics of sugar, ethanol and several secondary metabolites were documented. In addition, the effect of medium magnesium supplementation was considered based on previous works showing that $\mathrm{Mg}$ plays a crucial role in metabolism (Walker, Birch-Andersen, Hamburger, \& Kramhoft, 1982), cell division (Wolf, Trapani, \& Cittadini, 2008) and may reduce ethanol toxicity associated stress (Chun-Keng, Feng-Wu, \& Li-Jia, 2003; Dombek \& Ingram, 1986). The $S$. pombe strain used was selected in a previous study based on its ethanol resistance, fermentation performance and L-malic acid degradation capacity, as well as its resistance towards the dehydration conditions applied for starter preparation (Roca-Domènech et al., 2016).

\section{Materials and methods}

\subsection{Medium, microorganism and culture conditions}

The same flash-pasteurized Riesling must from the Palatinate region of Germany was used for all batch and fed-batch fermentations. Its sugar concentration was $191.9 \mathrm{~g} / \mathrm{L}$ combined glucose and fructose, the $\mathrm{pH}$ was 3.37 , the titratable acidity was $4.72 \mathrm{~g} / \mathrm{L}$ expressed as tartaric acid and the yeast assimilable nitrogen (YAN) concentration was $150 \mathrm{mg} / \mathrm{L} \mathrm{N}$. For nitrogen yeast nutrition, the must was supplemented with $0.3 \mathrm{~g} / \mathrm{L}$ of a complex supplement (Uvavital D, Eaton, Germany) and $0.2 \mathrm{~g} / \mathrm{L}$ of laboratory grade $\left(\mathrm{NH}_{4}\right)_{2} \mathrm{HPO}_{4}$ (ACS, Sigma Aldrich, EU). $\mathrm{Mg}$ supplemented must was produced by increasing the native $\mathrm{Mg}$ concentration of $45 \mathrm{mg} / \mathrm{L}$ with $\mathrm{MgSO}_{4}$ to reach $167 \mathrm{mg} / \mathrm{L} \mathrm{Mg}$.

$S$. pombe strain CECT11197 was obtained from the culture collection of the Department of Biochemistry and Biotechnology, University Rovira i Virgili, Tarragona, Spain and was pre-grown under aerobic conditions in YEPD (Yeast Extract Peptone Dextrose Medium, Fisher Scientific) in shaker flasks (150 rpm) for $40 \mathrm{~h}$ at $25^{\circ} \mathrm{C}$ to obtain a yeast starter for inoculations. Batch fermentations were conducted by adding this yeast starter to the entire amount of must in $5 \mathrm{~L}$ glass bottles (Schott Duran, Germany) sealed with suitable air locks to allow for fermentation gas release and to prevent air ingress. These fermentations were inoculated to a titer of $1 \times 10^{7}$ cells $/ \mathrm{mL}$ as determined by a Neubauer counting chamber with respect to the total must volume.

Fed-batch treatments were conducted according to Frohman and Mira de Orduña (2018). Briefly, a Fourier-Transform Near-Infrared (FTNIR) Spectrophotometer (MPA, Bruker, Germany) equipped with a suitable relfectance in-situ probe (IN271F, Bruker Optics Germany) was

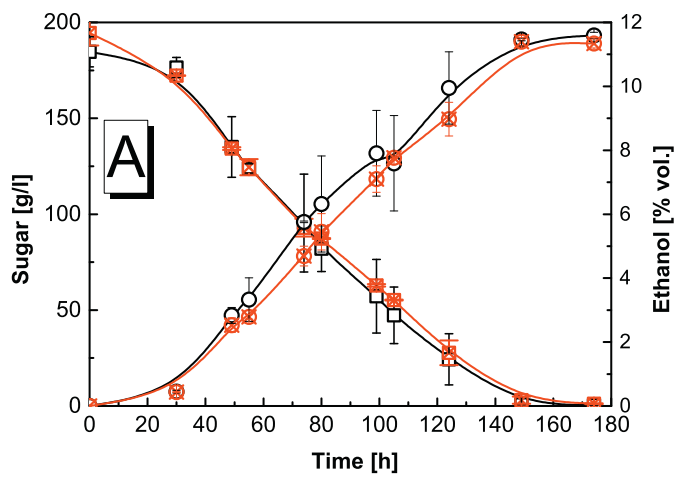

used to quantify the concentrations of sugars and ethanol in real-time based on previously established prediction models using the equipment's chemometric software (OPUS, Bruker, Germany). Sugar concentration data was then used to automatically control a peristaltic pump (Reglo ICC Digital Peristaltic Pump, 3-channels, Ismatec, WA) that delivered the fresh Riesling must (kept at $0{ }^{\circ} \mathrm{C}$ ) to the fermentation at such rates as to keep sugar concentrations stable at approximately $65 \mathrm{~g} / \mathrm{L}$ during fermentations. Fed-batch fermentations had a starting volume of $68 \mathrm{~mL}$ consisting of $45 \mathrm{~mL}$ of yeast starter and $23 \mathrm{~mL}$ of flashpasteurized Riesling must to obtain an initial sugar concentration of approximately $65 \mathrm{~g} / \mathrm{L}$. Inoculation occurred at a titer of $1 \times 10^{7}$ cells/ $\mathrm{mL}$ as determined by a Neubauer counting chamber with respect to the total final must volume to be delivered $(1.8 \mathrm{~L})$. During the initial phase of fed-batch fermentations (up to a volume of $500 \mathrm{~mL}$ ), the head space of fed-batch incubations was flushed with $\mathrm{CO}_{2}$ in order to prevent oxidation. All fermentations were carried out at $22 \pm 1{ }^{\circ} \mathrm{C}$.

\subsection{Sample taking, analytical methods and statistical analysis}

For chemical analyses, the biomass was removed by centrifugation ( $5 \mathrm{~min}, 15,000 \mathrm{~g}$ ) and the supernatant stored frozen $\left(-20^{\circ} \mathrm{C}\right)$ until analysis. YAN was measured by quantifying amino nitrogen according to the NOPA method (Dukes \& Butzke, 1998) and inorganic nitrogen by means of an enzymatic method for ammonia (Megazyme, Ireland). Sugars, ethanol, glycerol, acetic acid, lactic acid and malic acid were analysed with a HPLC system (Agilent 1260 Infinity, EU) equipped with a 64225A degasser, a G1310B isocratic pump, a GT329B autosampler, a G1316A column oven, a G1314F UV detector and a refractive index detector (RI-102, Shodex). Data acquisition and analysis were performed with the instrument software provided (Agilent OpenLab CDS Chemstation v.A02.09). The mobile phase consisted of $0.65 \mathrm{mM} \mathrm{H}_{2} \mathrm{SO}_{4}$ and was filtered prior to utilization $(0.22 \mu \mathrm{m}$, nylon, Millipore, Ireland). $500 \mu \mathrm{L}$ of sample was mixed with $4.5 \mathrm{~mL}$ of the mobile phase and cleaned up using a commercial solid phase extraction cartridge loaded with $200 \mathrm{mg}$ sorbent (Waters Oasis HLB $6 \mathrm{cc}$ ). $20 \mu \mathrm{L}$ sample was then injected and separated at $80^{\circ} \mathrm{C}$ on a PS-DVB phase (Aminex HPX-87H, $300 \times 7.8 \mathrm{~mm}$, Bio-Rad) at a flow rate of $0.5 \mathrm{~mL} / \mathrm{min}$. Sugars, ethanol and acids were quantified by refractive index while acetic acid was quantified by UV spectroscopy at $210 \mathrm{~nm}$. Acetaldehyde was measured enzymatically with a commercial test kit (Megazyme, UK). External calibration standards were used to validate all analyses.

All fermentations were carried out in triplicate and data representation and rate fittings were carried out using OriginLab Origin v7.0. Results were statistically analysed using the XLSTAT 19.5 statistical software package.

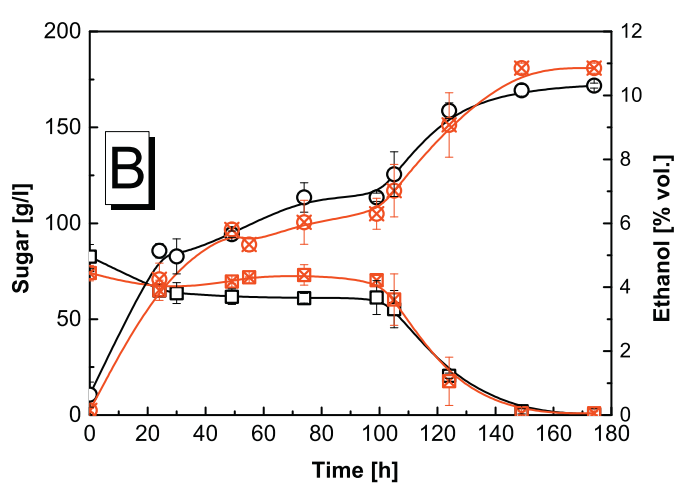

Fig. 1. Consumption of sugar $(\square)$ and production of ethanol (O) during traditional batch (A) and fed-batch fermentations (B). Fermentations with Mg supplementation represented by red symbols with crosses (sugar: $\bigotimes$; ethanol: $\bigotimes)$. Average values \pm SD shown $(n=3)$. (For interpretation of the references to colour in this figure legend, the reader is referred to the web version of this article.) 

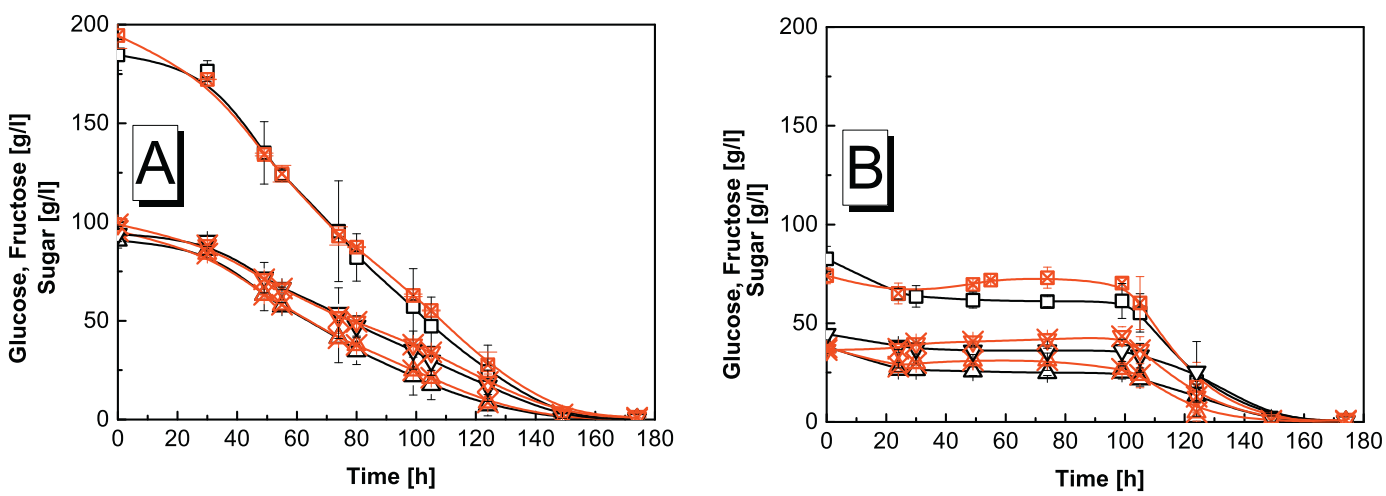

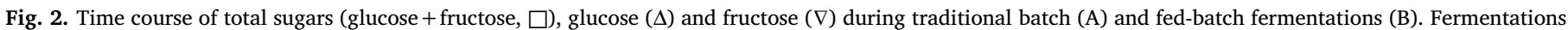

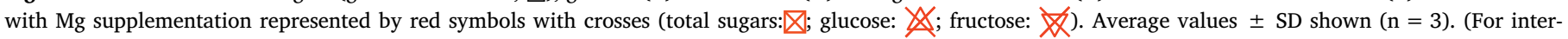
pretation of the references to colour in this figure legend, the reader is referred to the web version of this article.)

\section{Results}

\subsection{Sugars and ethanol}

Fig. 1 shows the time course of sugar and ethanol concentrations in traditional batch (A) and fed-batch (B) fermentations. Traditional batch fermentations without and with $\mathrm{Mg}$-supplementation reached dryness ( $<5 \mathrm{~g} / \mathrm{L}$ of sugar) after $149 \mathrm{~h}$. In fed-batch fermentations, sugars were kept constant at approximately $65 \mathrm{~g} / \mathrm{L}$ until all must was consumed and during this period $(100 \mathrm{~h}), 6-7 \%(\mathrm{v} / \mathrm{v})$ of ethanol were reached. After conclusion of the must-feeding phase, the residual sugar was also completely degraded after $149 \mathrm{~h}$ irrespective of $\mathrm{Mg}$ supplementation. All fermentations displayed a slight glucophilic sugar degradation behaviour that was not significantly influenced by the type of fermentation or Mg supplementation (Fig. 2). There was no statistically significant difference between the residual sugar concentrations of any of the treatments (Table 1). In spite of this, significant differences were found with regards to the final ethanol concentrations. Wines produced with the fed-batch technique had $0.55-1.3 \%(\mathrm{v} / \mathrm{v})$ less ethanol (Table 1).

\subsection{Malic acid degradation}

From an initial must concentration of $2.6 \mathrm{~g} / \mathrm{L}$, malic acid was rapidly degraded $(<60 \mathrm{~h}$ ) in traditional batch fermentations (Fig. 3). In fed-batch incubations, malic acid concentrations never exceeded $0.6 \mathrm{~g} /$ $\mathrm{L}$ and remained below the LOD for most of the duration of incubations. The higher initial malic acid concentration in the fed-batch treatment with added $\mathrm{Mg}$ was attributable to differences in the process control (must feeding rate). Except for this slight difference, Mg supplementation had no effect on the time course of malic or lactic acid levels, which stayed relatively constant throughout all fermentations. There was a slight trend towards higher final lactic acid concentrations in wines produced by the fed-batch technique, which was not statistically relevant (Fig. 3).

\subsection{Sugar induced osmotic stress response related metabolites}

Fig. 4 shows the kinetics of several sugar induced osmotic stress associated fermentation by-products in traditional batch and fed-batch fermentations. Supplementation with $\mathrm{Mg}$ led to slightly different kinetics of glycerol and acetic acid in some incubations. However, the effects were not consistent and Mg supplmentation had no statistically significant effect on the final values (Table 1) of any of the metabolites. In contrast, significant differences were observed with regards to the kinetics and the final values between traditional batch and fed-batch fermentations. In batch fermentations, glycerol levels increased rapidly up to $70-80 \mathrm{~h}$ of fermentation time and then stayed constant. In fedbatch incubations, glycerol formation already levelled off after $30 \mathrm{~h}$ and final glycerol concentrations were approximately $20 \%$ lower (Table 1 ). The differences were striking with regards to acetic acid kinetics and final values (Fig. 4, Table 1). A strong initial production of acetic acid in traditional batch fermentations transitioned to a slower production phase after approximately $90 \mathrm{~h}$ resulting in a mean final concentration of $600 \mathrm{mg} / \mathrm{L}$ acetic acid across all batch incubations. In contrast, acetic acid never exceeded $220 \mathrm{mg} / \mathrm{L}$ in fed-batch incubations (Fig. 4) and no acetic acid was detectable in any of the fed-batch incubations after $25 \mathrm{~h}$ of incubation time (Table 1). The course of acetaldehyde concentrations followed typical kinetics with an initial increase followed by a partial reuptake (Jackowetz, Dierschke, \& Mira de Orduña, 2011). Peak and final acetaldehyde concentrations were similar across all incubations (Fig. 4). There was a trend towards lower residual acetaldehyde concentrations ( $40 \%$ less) in wines produced by the fed-batch technique, which was not statistically significant (Table 1).

\section{Discussion}

Shizosaccharomyces pombe is a grape must fermentation associated non-Saccharomyces yeast with significant potential for winemaking (Benito et al., 2016). S. pombe strains have been shown to possess the ability to completely convert grape sugars to alcohol, and to degrade malic acid (Dharmadhikari \& Wilker, 1998), which typically has to be

Table 1

Final concentrations of various fermentation parameters. Values displayed are means of triplicate experiments \pm SD. Different superscript letters indicate statistical significance between averages at $\mathrm{p}<0.05$.

\begin{tabular}{|c|c|c|c|c|c|c|c|}
\hline & Total Sugar (g/L) & Ethanol (\% vol.) & Glycerol (g/L) & Acetic ac. $(\mathrm{g} / \mathrm{L})$ & Acetaldehyde (mg/L) & Malic ac. (g/L) & Lactic ac. (g/L) \\
\hline Batch & $0.81 \pm 0.08^{\mathrm{a}}$ & $11.47 \pm 0.10^{\mathrm{a}}$ & $11.96 \pm 1.11^{\mathrm{a}}$ & $0.55 \pm 0.07^{\mathrm{a}}$ & $67.54 \pm 26.45^{\mathrm{a}}$ & n.d. & $0.12 \pm 0.00^{\mathrm{a}}$ \\
\hline Batch $+\mathrm{Mg}$ & $3.04 \pm 1.85^{\mathrm{a}}$ & $11.40 \pm 0.13^{\mathrm{ab}}$ & $11.64 \pm 0.05^{\mathrm{ab}}$ & $0.66 \pm 0.04^{\mathrm{a}}$ & $50.52 \pm 2.60^{\mathrm{a}}$ & n.d. & $0.12 \pm 0.00^{\mathrm{a}}$ \\
\hline Fed-Batch & $1.94 \pm 1.33^{\mathrm{a}}$ & $10.16 \pm 0.18^{c}$ & $9.52 \pm 0.90^{\mathrm{ab}}$ & n.d. & $35.95 \pm 1.32^{\mathrm{a}}$ & n.d. & $0.17 \pm 0.02^{\mathrm{a}}$ \\
\hline Fed-Batch $+\mathrm{Mg}$ & $0.96 \pm 0.79^{\mathrm{a}}$ & $10.85 \pm 0.16^{\mathrm{b}}$ & $8.83 \pm 0.49^{b}$ & n.d. & $39.94 \pm 2.5^{\mathrm{a}}$ & n.d. & $0.16 \pm 0.01^{\mathrm{a}}$ \\
\hline
\end{tabular}

n.d.: not detected. 


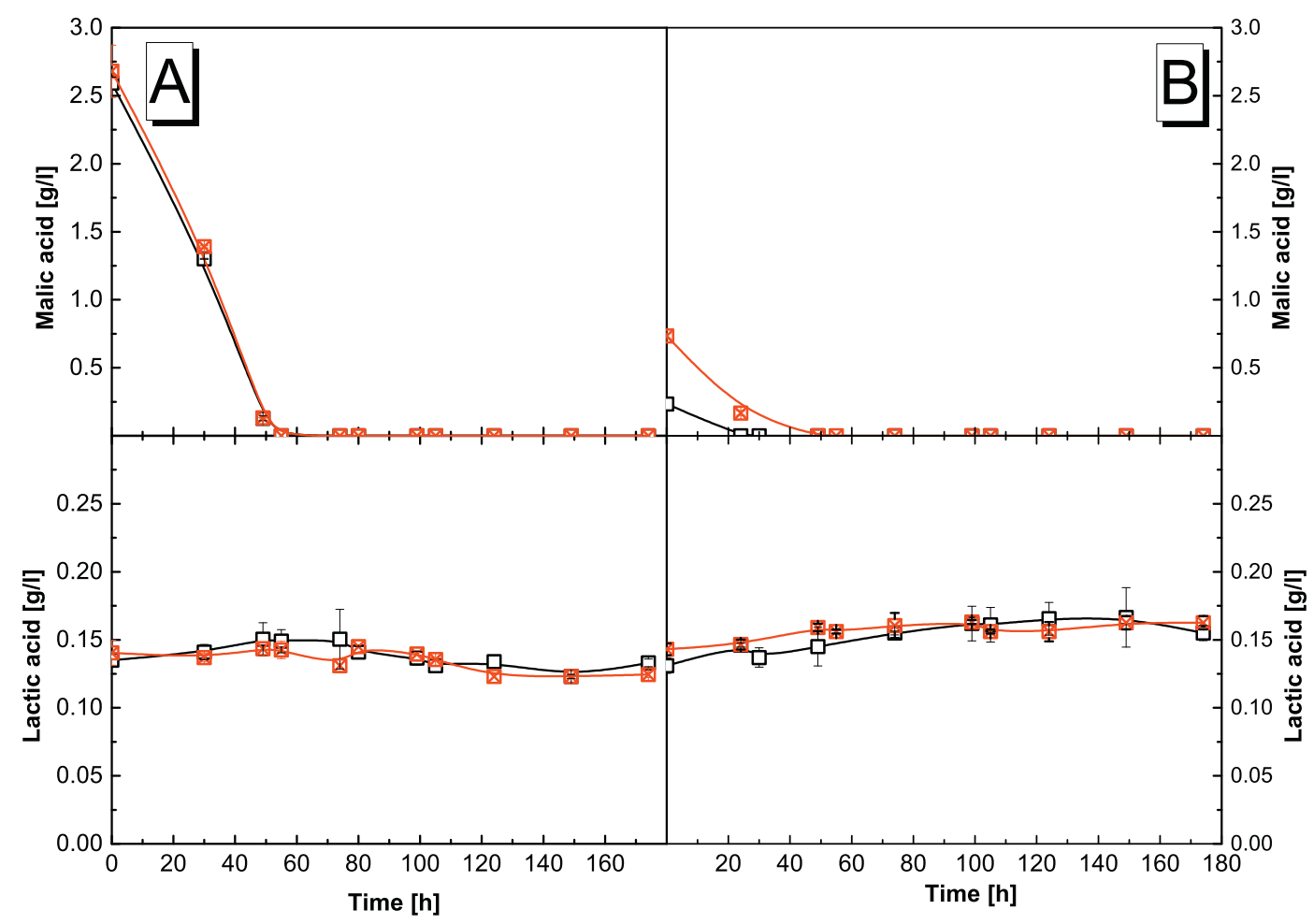

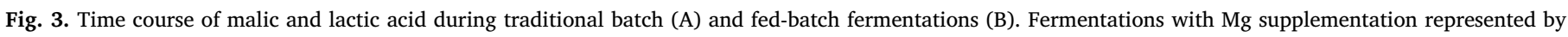
symbols with crosses. Average values $\pm \operatorname{SD}$ shown $(n=3)$.

achieved during a malolactic fermentation (Sumby, Grbin, \& Jiranek, 2014). In addition, its production of aldehyde compounds may be of interest for red wine colour development (Morata et al., 2012; Mylona et al., 2016).

In this work, its utilization as sole production organism was studied in monoseptic white grape must fermentations in traditional batch incubations, as well as fed-batch fermentations that have been shown to improve fermentation performance of $S$. cerevisiae and reduce the production of undesirable fermentation by-products (Frohman \& Mira de Orduña, 2013). In addition, grape must supplementation with $\mathrm{Mg}$ was investigated. In $S$. cerevisiae, magnesium has been shown to act as a growth enhancer and to increase ethanol tolerance (Walker et al., 1982). Mg supplementation has also been associated with improved growth and ethanol tolerance in S. pombe (Hu, Bai, \& An, 2003). However, in this study, Mg supplementation was not found to have a consistent effect on the time course or final values of any of the metabolites studied. Although the natural $\mathrm{Mg}$ concentration of the grape must used ( $45 \mathrm{mg} / \mathrm{L} \mathrm{Mg}$ ) was relatively low with regards to typical must $\mathrm{Mg}$ levels reported in the literature (50-200 mg/L Mg, Margalit, 2016), it is possible that it was still too high to cause a Mg deficiency. Since specific chelation for $\mathrm{Mg}$ sequestration is difficult, the effect of $\mathrm{Mg}$ may be better studied in synthetic grape must fermentations.

Overall, the differences caused by the fermentation mode were notable. While sugar degradation was complete in all treatments, final alcohol concentrations were slightly reduced in wines produced by the fed-batch technique. In studies with $S$. cerevisiae, fed-batch incubations did not lead to ethanol reductions compared with the traditional batch approach (Frohman \& Mira de Orduña, 2013). As much as an ethanol reduction would be desirable considering the climate change associated increase in wine ethanol concentrations and its implications (Mira de Orduña, 2010), it is suggested that the results obtained in this study were an artefact of the technique applied rather than a physiological response to lower sugar concentrations. Specifically, the $\mathrm{CO}_{2}$ flushing applied to prevent oxidation in the small initial fed-batch fermentation volume is expected to have caused ethanol stripping.
Unlike malolactic fermentation (MLF) by lactic acid bacteria (Lonvaud-Funel, 1999), malic acid degradation by $S$. pombe does not lead to lactic acid formation, which can lead to lactic notes from formation of ethyl lactate after esterification. Rather, malic acid metabolism by $S$. pombe leads to formation of ethanol and $\mathrm{CO}_{2}$ (Benito et al., 2016). In both fermentation treatments, malic acid was degraded below the detection threshold of the method applied. Because of the high initial cell density present in fed-batch fermentations, must was essentially depleted from malic acid upon introduction to fed-batch fermentations. Lactic acid concentrations remained almost constant in all treatments, confirming the significant potential of $S$. pombe for biological deacidification especially in high acidity musts.

The polyol glycerol is an alcoholic fermentation by-product and plays significant roles in yeast physiology such as maintaining cellular redox homeostasis and functioning as an osmoprotectant (Michnick, Roustan, Remize, \& Barre, 1997; Scanes, Hohmann, \& Priori, 1998). Consequently, under high sugar induced osmotic pressure, glycerol formation is increased and correlates with formation of acetic acid in $S$. cerevisiae (Pigeau \& Inglis, 2007). A recent study investigating the alcoholic fermentation of $S$. cerevisiae showed that the reduced osmotic stress afforded by a fed-batch approach led to a $45 \%$ reduction in final glycerol and a $80 \%$ reduction in final acetic acid levels as compared with the traditional batch approach (Frohman \& Mira de Orduña, 2013). In traditional batch fermentations, the $S$. pombe strain CECT11197 used in this study yielded acetic acid concentrations $(0.55 \mathrm{~g} / \mathrm{L})$ that were similar to those reported by Mylona et al. (2016) for another $S$. pombe strain $(0.51 \mathrm{~g} / \mathrm{L}$ for strains 7VA) but significantly lower than those reported by Miljić, Puškaš, Vučurović, and Muzalevski (2017) and Mylona et al. (2016), for strains 2139 and 938 which exceeded $1 \mathrm{~g} / \mathrm{L}$ of acetic acid. Conversely, Mylona et al. (2016) and especially Du Plessis et al. (2017) reported much lower levels for $S$. pombe strains than ranged between $0.07 \mathrm{~g} / \mathrm{L}$ (expressed as volatile acidity) and $0.35 \mathrm{~g} / \mathrm{L}$ acetic acid. In this study, the fed-batch approach allowed obtaining wines devoid of acetic acid while glycerol levels still remained higher than those repoted by Mylona et al. (2016). 


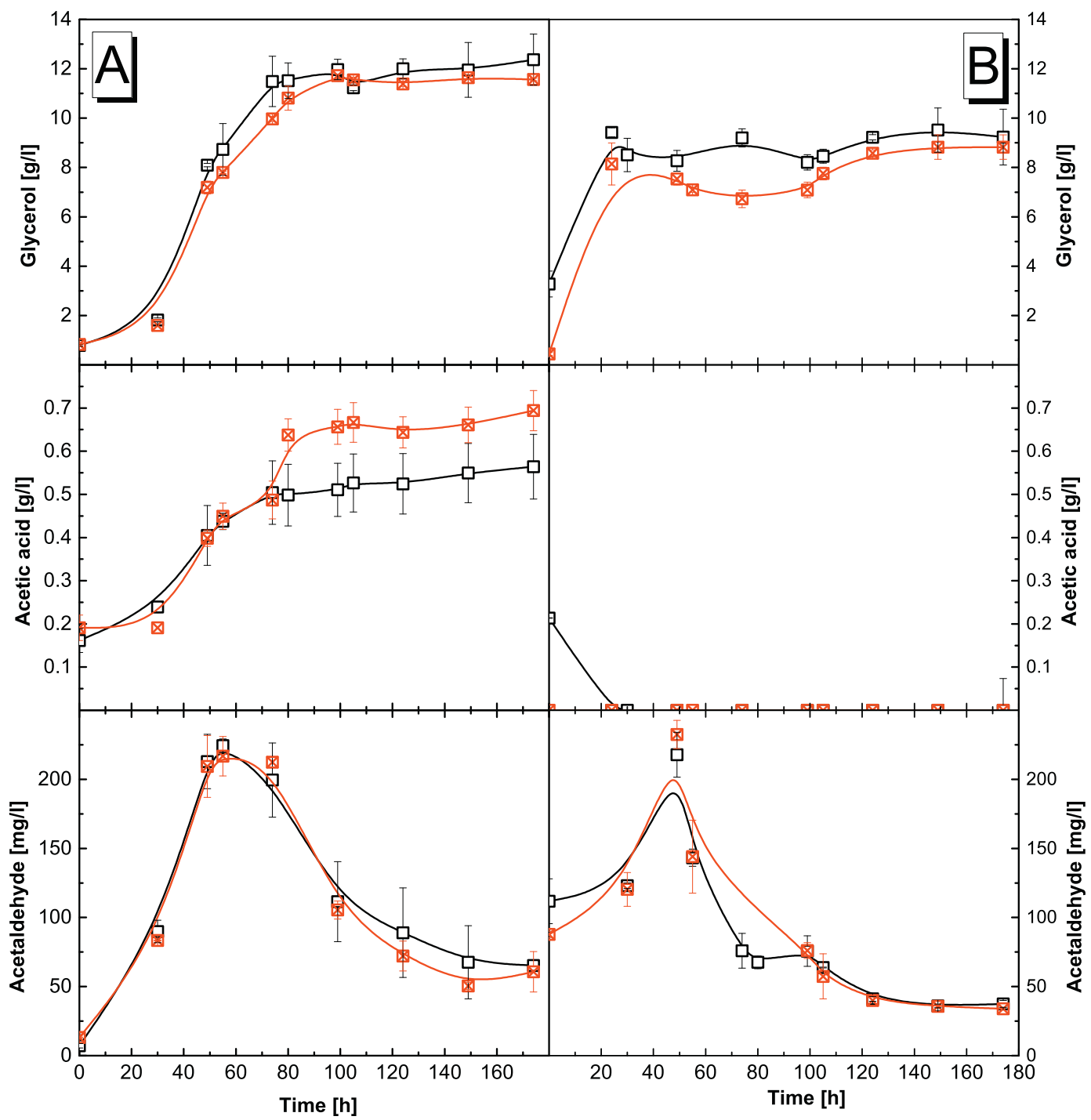

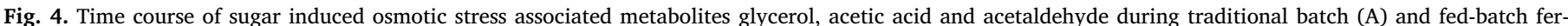
mentations (B). Fermentations with Mg supplementation represented by symbols with crosses. Average values \pm SD shown $(\mathrm{n}=3$ ).

Accordingly, application of the fed-batch technique may allow to greatly reduce volatile acidity even with strains that produce significant amounts of acetic acid in traditional batch culture, while maintaining relatively high levels of glycerol, which is associated with positive sensory notes in wine (Lubbers, Verret, \& Voulley, 2001; Noble \& Bursick, 1984).

Acetaldehyde is the major carbonyl compound formed during alcoholic fermentation and has implications for sensory qualities and stability of wines as well as for the use of the wine preservative $\mathrm{SO}_{2}$ (Jackowetz \& Mira de Orduña, 2013). Compared with other wine associated yeast, $S$. pombe produced relatively large amounts of acetaldehyde in resting cell and grape must incubations (Li \& Mira de Orduña, 2011, 2017). While this metabolic property may be interesting in red wine fermentations where acetaldehyde contributes to the stabilization of red wine colours (Benito, Calderón, \& Benito, 2017; Mylona et al., 2016), in white wines it is considered undesirable since acetaldehyde will bind signifcant quantities of $\mathrm{SO}_{2}$ (Jackowetz et al., 2011), a wine conservative whose levels are sought to be limited. In this study, there was a trend towards lower acetaldehyde levels in fed-batch treatments. In fact, the residual acetaldehyde concentrations of $40 \mathrm{mg}$ / $\mathrm{L}$ in wines produced by the fed-batch technique in this study were congruent with the average concentrations measured in 127 commercial white wines in a recent study (Jackowetz \& Mira de Orduña, 2013).
Hence, in spite of the higher known acetaldehyde production potential of $S$. pombe strains, application of $S$. pombe strain CECT11197 with the fed-batch technique allowed obtaining wines with residual acetaldehyde levels comparable to current commercial standards. The acetaldehyde residues obtained with the $S$. pombe strains selected by Mylona et al. (2016) were even lower in batch fermenations. Accordingly, application of these superior strains with a fed-batch technique may allow to further reduce acetaldehyde levels.

\section{Conclusions}

The current work demonstrated the suitability of a selected Shizosaccharomyces pombe strain for monoseptic fermentations of white grape juice. Its ability to completely convert grape sugars to alcohol and its strong malic acid degradation capacity may be advantageous for a number of vinification challenges including acidic white musts. Applying a novel fed-batch technique, it was possible to avoid formation of acetic acid. The application of suitable strains reported elsewhere with the innovative fed-batch fermentation approach may provide for an efficient utilization of $S$. pombe in white winemaking. 


\section{Acknowledgements}

This work was supported by grant AGL2012-40018 from the Spanish Ministry of Science and Innovation. G. Roca-Domènech acknowledges Rovira i Virgili University for the doctoral fellowship 2014PMF-PIPF-47.

\section{References}

Benito, Á., Calderón, F., \& Benito, S. (2017). The combined use of Schizosaccharomyces pombe and Lachancea thermotolerans-Effect on the anthocyanin wine composition. Molecules, 22(5), 739.

Benito, Á., Jeffares, D., Palomero, F., Calderón, F., Bai, F. Y., Bähler, J., \& Benito, S. (2016). Selected Schizosaccharomyces pombe strains have characteristics that are beneficial for winemaking. PLOS ONE, 11, e0151102.

Benito, S., Palomero, F., Morata, A., Calderón, F., Palmero, D., \& Suárez-Lepe, J. A. (2013). Physiological features of Schizosaccharomyces pombe of interest in making of white wines. European Food Research and Technology, 236, 29-36.

Chun-Keng, H., Feng-Wu, B., \& Li-Jia, A. (2003). Enhancing ethanol tolerance of a selfflocculating fusant of Schizosaccharomyces pombe and Saccharomyces cerevisiae by $\mathrm{Mg}^{2+}$ via reduction in plasma membrane permeability. Biotechnology Letters, 25, 1191-1194.

Ciani, M., Comitini, F., Mannazzu, I., \& Domizio, P. (2010). Controlled mixed culture fermentation: A new perspective on the use of non-Saccharomyces yeasts in winemaking. FEMS Yeast Research, 10, 123-133.

Ciani, M., \& Maccarelli, F. (1998). Oenological properties of non-Saccharomyces yeasts associated with wine-making. World Journal of Microbiology and Biotechnology, 14, 199-203.

Contreras, A., Hidalgo, C., Henschke, P. A., Chambers, P. J., Curtin, C., \& Varela, C. (2014). Evaluation of non-Saccharomyces yeasts for the reduction of alcohol content in wine. Applied and Environmental Microbiology, 80, 1670-1678.

Dharmadhikari, M. R., \& Wilker, K. L. (1998). Deacidification of high malate must with Schizosaccharomyces pombe. American Journal of Enology and Viticulture, 49, 408-412.

Dombek, K. M., \& Ingram, L. O. (1986). Magnesium limitation and its role in apparent toxicity of ethanol during yeast fermentation. Applied and Environmental Microbiology, 52, 975-981.

Domizio, P., Liu, Y., Bisson, L. F., \& Barile, D. (2017). Cell wall polysaccharides released during the alcoholic fermentation by Schizosaccharomyces pombe and S. japonicus: Quantification and characterization. Food Microbiology, 61, 136-149.

Du Plessis, H., Du Toit, M., Hoff, J., Hart, R., Ndimba, B., \& Jolly, N. (2017). Characterisation of non-Saccharomyces yeasts using different methodologies and evaluation of their compatibility with malolactic fermentation. South African Journal of Enology and Viticulture, 38, 46-63.

Dukes, B. C., \& Butzke, C. E. (1998). Rapid determination of primary amino acids in grape juice using an $o$-phtalaldehyde/N-acetyl-L-cysteine spectrophotometric assay. American Journal of Enology and Viticulture, 49, 127-134.

Fleet, G. H., Lafon-Lafourcade, S., \& Ribereau-Gayon, P. (1984). Evolution of yeasts and lactic acid bacteria during fermentation and storage of Bordeaux wines. Applied and Environmental Microbiology, 48, 1034-1038.

Frohman, C. A., \& Mira de Orduña, R. (2013). Cellular viability and kinetics of osmotic stress associated metabolites of Saccharomyces cerevisiae during traditional batch and fed-batch alcoholic fermentations at constant sugar concentrations. Food Research International, 53, 551-555.

Frohman, C. A., \& Mira de Orduña, R. (2018). The substratostat - an automated near-infrared spectroscopy-based variable-feed system for fed-batch fermentations of grape musts OENO One. In Press.

Hoffman, C. S., Wood, V., \& Fantes, P. A. (2015). An ancient yeast for young geneticists: A primer on the Schizosaccharomyces pombe model system. Genetics, 201, 403-423.

Hu, C. K., Bai, F. W., \& An, L. J. (2003). Enhancing ethanol tolerance of a self-flocculating fusant of Schizosaccharomyces pombe and Saccharomyces cerevisiae by $\mathrm{Mg}^{2+}$ via reduction in plasma membrane permeability. Biotechnology Letters, 25, 1191-1194.

Jackowetz, J. N., Dierschke, S. E., \& Mira de Orduña, R. (2011). Multifactorial analysis of acetaldehyde kinetics during alcoholic fermentation by Saccharomyces cerevisiae. Food Research International, 44, 310-316.

Jackowetz, J. N., \& Mira de Orduña, R. (2013). Survey of $\mathrm{SO}_{2}$ binding carbonyls in 237 red and white table wines. Food Control, 32, 687-692.

Koukou, A. I., Tsoukatos, D., \& Drainas, C. (1990). Effect of ethanol on the phospholipid and fatty acid content of Schizosaccharomyces pombe membranes. Journal of General Microbiology, 136, 1271-1277.
Li, E., \& Mira de Orduña, R. (2011). Evaluation of the acetaldehyde production and degradation potential of 26 enological Saccharomyces and non-Saccharomyces yeast strains in a resting cell model system. Journal of Industrial Microbiology \& Biotechnology, 38, 1391-1398.

Li, E., \& Mira de Orduña, R. (2017). Acetaldehyde kinetics of enological yeast during alcoholic fermentation in grape must. Journal of Industrial Microbiology \& Biotechnology, 44, 229-236.

Lonvaud-Funel, A. (1999). Lactic acid bacteria in the quality improvement and depreciation of wine. Antonie Van Leeuwenhoek, 76, 317-331.

Lubbers, S., Verret, C., \& Voulley, A. (2001). The effect of glycerol on the perceived aroma of a model wine and a white wine. Lebensmittel-Wissenschaft \& Technologie, 34, 262-265.

Margalit, Y. (2016). Concepts in wine chemistry. Board and Bench Publishing.

Michnick, S., Roustan, J. L., Remize, F., \& Barre, P. (1997). Modulation of glycerol and ethanol yields during alcoholic fermentation in Saccharomyces cerevisiae strains overexpressed or disrupted for GPD1 encoding glycerol 3-phosphate dehydrogenase. Yeast, 13, 783-793.

Miljić, U., Puškaš, V., Vučurović, V., \& Muzalevski, A. (2017). Fermentation characteristics and aromatic profile of plum wines produced with indigenous microbiota and pure cultures of selected yeast. Journal of Food Science, 82, 1443-1450.

Mira de Orduña, R. (2010). Climate change associated effects on grape and wine quality and production. Foodservice Research International, 43, 1844-1855.

Morata, A., Benito, S., Loira, I., Palomero, F., Gonzalez, M. C., \& Suarez-Lepe, J. A. (2012). Formation of pyranoanthocyanins by Schizosaccharomyces pombe during the fermentation of red must. International Journal of Food Microbiology, 159, 47-53.

Mylona, A. E., Del Fresno, J. M., Palomero, F., Loira, I., Bañuelos, M. A., Morata, A., .. Suárez-Lepe, J. A. (2016). Use of Schizosaccharomyces strains for wine fermentation: Effect on the wine composition and food safety. International Journal of Food Microbiology, 232, 63-72.

Noble, A. C., \& Bursick, G. F. (1984). The contribution of glycerol to perceived viscosity and sweetness in white wine. American Journal of Enology and Viticulture, 35, $110-112$.

Padilla, B., Gil, J. V., \& Manzanares, P. (2016). Past and future of non- Saccharomyces yeasts: From spoilage microorganisms to biotechnological tools for improving wine aroma complexity. Frontiers in Microbiology, 7, 1-20.

Peinado, R. A., Maestre, O., Mauricio, J. C., \& Moreno, J. J. (2009). Use of a Schizosaccharomyces pombe mutant to reduce the content in gluconic acid of must obtained from rotten grapes. Journal of Agricultural and Food Chemistry, 57, 2368-2377.

Petersen, J., \& Russell, P. (2016). Growth and the environment of Schizosaccharomyces pombe. Cold Spring Harbor Protocols, 3, 1-17.

Pigeau, G. M., \& Inglis, D. L. (2007). Response of wine yeast Saccharomyces cerevisiae aldehyde dehydrogenases to acetaldehyde stress during Icewine fermentation. Journal of Applied Microbiology, 103, 1576-1586.

Pretorius, I. S., Van der Westhuizen, T. J., \& Augustyn, O. P. H. (1999). Yeast biodiversity in vineyards and wineries and its importance to the south African wine industry: A review. South African Journal of Enology and Viticulture, 2, 61-75.

Queiroz, H., \& Pareilleux, A. (1990). Applied microbiology biotechnology growth kinetics of Schizosaccharomyces pombe under various culture conditions: Influence of $\mathrm{pH}$ malate, ethanol and oxygenation. Applied Microbiology and Biotechnology, 33, 578-581.

Roca-Domènech, G., López- Martínez, G., Tirado, V., Borrull, A., Candelas, Ó., Rozès, N., \& Cordero-Otero, R. (2016). Viability enhancement of Schizosaccharomyces pombe cells during desiccation stress. Journal of Microbiology Research, 6, 82-91.

Scanes, K. T., Hohmann, S., \& Priori, B. A. (1998). Glycerol production by the yeast Saccharomyces cerevisiae and its relevance to wine: A review. South African Journal of Enology and Viticulture, 19, 17-24.

Silva, S., Ramón-Portugal, F., Andrade, P., Abreu, S., Texeira, M. D. F., \& Strehaiano, P. (2003). Malic acid consumption by dry immobilized cells of Schizosaccharomyces pombe. American Journal of Enology and Viticulture, 54, 50-55.

Sumby, K. M., Grbin, P. R., \& Jiranek, V. (2014). Implications of new research and technologies for malolactic fermentation in wine. Applied Microbiology and Biotechnology, 98, 8111-8132.

Taillandier, P., Gilis, M., \& Strehaiano, P. (1995). Deacidification by Schizosaccharomyces: Interactions with Saccharomyces. Journal of Biotechnology, 40, 199-205.

Walker, G. M., Birch-Andersen, A., Hamburger, K., \& Kramhoft, B. (1982). Magnesiuminduced mitochondrial polymorphism and changes in respiratory metabolism in the fission yeast, Schizosaccharomyces pombe. Carlsberg Research Communications, 47, 205-214.

Wolf, F. I., Trapani, V., \& Cittadini, A. (2008). Magnesium and control of cell proliferation: Looking for a needle in a haystack. Journal of the Institute of Brewing, 21, 83-91. 